\title{
Territorios hidrosociales en las geografías altoandinas del Norte de Chile: modernización y conflictos en la región de Tarapacá.
}

Territoires hydro sociaux dans les hauts plateaux andins du Chili du Nord: modernisation et conflits dans la région de Tarapacá Hydrosocial territories in andean geographies of Northern Chile: modernization and conflicts in the Tarapacá region

Manuel Méndez y Hugo Romero

\section{OpenEdition}

Journals

Edición electrónica

URL: http://journals.openedition.org/ideas/7512

DOI: $10.4000 /$ ideas. 7512

ISSN: 1950-5701

Editor

Institut des Amériques

Referencia electrónica

Manuel Méndez y Hugo Romero, «Territorios hidrosociales en las geografías altoandinas del Norte de Chile: modernización y conflictos en la región de Tarapacá. », IdeAs [En línea], 15 | 2020, Publicado el 01 marzo 2020, consultado el 25 marzo 2020. URL : http://journals.openedition.org/ideas/7512 ; DOI : https://doi.org/10.4000/ideas.7512

Este documento fue generado automáticamente el 25 marzo 2020.

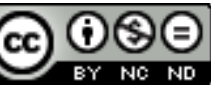

IdeAs - Idées d'Amériques est mis à disposition selon les termes de la licence Creative Commons Attribution - Pas d'Utilisation Commerciale - Pas de Modification 4.0 International. 


\section{Territorios hidrosociales en las geografías altoandinas del Norte de Chile: modernización y conflictos en la región de Tarapacá1.}

Territoires hydro sociaux dans les hauts plateaux andins du Chili du Nord: modernisation et conflits dans la région de Tarapacá

Hydrosocial territories in andean geographies of Northern Chile: modernization and conflicts in the Tarapacá region

Manuel Méndez y Hugo Romero

1 Abordar los conflictos en torno al agua desde una perspectiva hidrosocial es reconocer el carácter complejo e híbrido del fenómeno, entendiéndolo como un proceso continuamente reconstituido por diversos actores socionaturales. Esta perspectiva confronta la visión unidimensional a través de la cual diversos estudios económicos, bio-físicos, climáticos e ingenieriles abordan las disputas en torno al agua, ignorando los aspectos históricos, políticos y de relaciones de poder. A través del lente de la ecología política, el presente trabajo analiza los conflictos por el agua en un espacio donde convergen intereses socioculturales, ambientales, políticos y económicos, en un contexto de gran variabilidad climática y un extremo desequilibrio de la distribución de la riqueza: el altiplano andino de la región de Tarapacá ubicado en el borde oriental del Desierto de Atacama.

2 A partir del trabajo seminal de Carl Bauer (1995), se han realizado diversos aportes al entendimiento de los conflictos por el agua en Chile (Budds J., 2004 y 2009; Molina F., 2012; Romero H., et al.., 2012a; Prieto M., 2015 y 2016; Méndez M. y H. Romero, 2019, entre otros). No obstante, la mayoría de estos se han centrado en el periodo post dictadura (1973-1990). Desde una perspectiva geo-histórica, el presente trabajo avanza en el reconocimiento y la comprensión de los contextos sociales, culturales y ambientales que interactúan en la producción discursiva y material de los territorios 
hidrosociales y cómo estas distintas concepciones entran en conflicto durante la "modernización" de la región. De esta forma, se siguen las premisas planteadas por Scott (1998) y Elden (2010) para la comprensión de la modernización del territorio, y las propuestas de Worster (1985), Linton (2010) y Lansing (2007) para la comprensión de la modernización del agua.

El texto se desarrolla de la siguiente forma: en una primera instancia se presentan los aspectos teórico-conceptuales y metodológicos que se utilizaron para estudiar la producción de los territorios hidrosociales en la región. Posteriormente, y a través de la consideración de estudios arqueológicos, históricos, paleoclimáticos y geográficos, se analiza la producción de los territorios hidrosociales multisituados de Tarapacá. Finalmente, se desarrolla un estudio de caso en las comunidades ${ }^{2}$ andinas de Lirima y Cancosa, a través del cual se pone en evidencia los cambios discursivos y materiales de la producción territorial durante el último siglo. En el desarrollo de este mismo caso, se presta particular atención a los efectos culturales y materiales que tuvo la introducción de la legislación neoliberal y la actividad minera moderna en estas dos comunidades indígenas.

\section{Aspectos teóricos y metodológicos del estudio: el territorio y el agua visto desde la ecología política.}

4 Siguiendo los lineamientos del materialismo histórico-geográfico propuestos por Harvey (1996), la presente investigación aborda el espacio geográfico desde una perspectiva dialéctica, en la cual naturaleza y sociedad no existen de forma individual, ni tampoco antes que los procesos, flujos y relaciones que los constituyen indisolublemente. De igual forma, se asume que los procesos socionaturales se encuentran intrínsecamente ligados a la dinámica geográfica e histórica particular de los lugares donde se producen, influenciados de mayor o menor manera por dinámicas geohistóricas de regiones adyacentes y lejanas. En otros términos, la socio-naturaleza es "producida" por su contexto temporal y espacial particular (Lefebvre H., 2000; Smith N., 2008).

5 Sobre la base de lo anteriormente planteado, se comprenderá al territorio como un proceso de construcción socionatural del espacio geográfico, en el cual las personas incorporan en sus estructuras socioculturales las características del paisaje en el que habitan, al mismo tiempo que plasman en él la complejidad de sus propias características socioculturales (Aliste E., 2010).

6 En esta misma perspectiva, Elden (2010) propone que todo examen del territorio obedece a una interrogante histórico-geográfica de las condiciones complejas y multivariadas que posibilitan los hechos y fenómenos socioambientales tal cual se presentan. Además, propone que un análisis territorial implica comprender las condiciones textuales (discursivas) y contextuales (geohistóricas) en las cuales se producen sus significados, perspectiva que denomina "genealogía del territorio". Al encontrarse constituido por su contexto histórico y geográfico particular, cada territorio contiene propiedades únicas y dinámicas, que lo individualizan respecto a otros. No obstante, los diferentes territorios se pueden presentar de forma adyacente, distante o incluso superpuesta (Méndez M. y H. Romero, 2018). 
7 En el caso del agua, Swyngedouw (2015) plantea que este elemento es un "híbrido socionatural" que fusiona los aspectos físicos, biológicos, sociales, políticos, económicos y culturales, entre otros. El estudio de este proceso hidrosocial implica un examen histórico de los actores involucrados en su co-producción, además de la comprensión de las relaciones multiescalares de control y poder que se materializan en el proceso de construcción (Swyngedouw E., 1999; Smith N., 2008; Boelens R., et al.., 2016).

Berkes y Folke (2000) han reconocido la necesidad de investigar estos temas como complejos sistemas sociecológicos, cuya capacidad de resiliencia y adaptabilidad al cambio, tanto de las autoregulaciones de los ecosistemas naturales como de los actores, organizaciones e instituciones sociales dependen de la existencia de formas de gobernanza adaptativa operacionalizadas sobre la base de la co-gestión emprendida por el capital social, focalizado en la existencia de redes, lenguajes y confianza.

9 Nuestra investigación utiliza la definición de territorios hidrosociales propuesta por Boelens, et al.., (2016), como un sistema socioambiental de interacciones multiescalares, donde aspectos culturales (sistemas epistemológicos), materiales (prácticas cotidianas), institucionales y ambientales coproducen los diferentes significados y flujos materiales del agua.

Por otro lado, Scott (1998) propone que la modernización es un mecanismo de simplificación de la realidad para lograr un mejor control sobre la naturaleza y la sociedad, proceso que se encuentra asociado a la creación de los Estados modernos, los cuales buscaban "legibilizar" (medir, codificar y simplificar) la tenencia de la tierra y la propiedad de la naturaleza, con fines impositivos y administrativos. Según Scott (1998), la medición se realiza principalmente a través de catastros y cartografías. La codificación se materializaba discursivamente a través de la imposición de una concepción científica-occidental, la cual se pone en práctica a través de la legislación. Estos procesos previos, creaban conjuntamente la simplificación de la naturaleza, a través de su significación unidimensional económica, por la cual pasa a ser un "recurso natural".

11 Siguiendo este mismo orden de ideas, Linton (2010) propone que el agua deviene moderna cuando este elemento se aísla de los aspectos socioculturales (el agua se reduce a sus aspectos "naturales") y cuando su definición química $\left(\mathrm{H}_{2} \mathrm{O}\right)$ y medición (unidades de volumen y/o tiempo-volumen) se vuelven universales. Asimismo, Worster (1985), Lansing (1997) y Linton (2010) proponen que los "expertos" (académicos y/o actores institucionales) juegan un rol esencial en la imposición y hegemonización del agua moderna.

De esta forma, la presente investigación se plantea dos objetivos. El primero de ellos se centra en identificar y analizar los aspectos discursivos y materiales de largo plazo de la producción moderna de los territorios hidrosociales de la región de Tarapacá. El segundo objetivo, plantea analizar, desde la realización de un estudio de caso de las comunidades altoandinas de Lirima y Cancosa, los aspectos discursivos y materiales de la modernización de los territorios hidrosociales, así como también los procesos de conflictos asociados a esta modernización.

13 En términos metodológicos, para llevar a cabo el primer objetivo se recurrió a una exhaustiva revisión de información secundaria contenida en estudios históricos, antropológicos, climáticos y paleoclimáticos de la región. El foco de esta revisión estuvo centrado en establecer un panorama temporal y territorial de la disponibilidad 
superficial y subterránea del agua en la región. Asimismo, se estableció, a escala regional, un resumen de los principales aspectos materiales (adaptabilidad socioambiental) que participaron en la producción de los territorios hidrosociales regionales durante los periodos prehispánico y pre-moderno. Posteriormente, se estableció una cronología de los principales aspectos discursivos que participan en el proceso de modernización de los territorios hidrosociales regionales. Para complementar este último análisis, se utilizó la información recolectada a través de entrevistas no estructuradas realizadas a actores claves de las comunidades y la administración comunal, metodología que será analizada en el siguiente apartado.

Para la realización del segundo objetivo, se utilizaron dos metodologías de recolección y análisis de información; el desarrollo de la observación participante y la aplicación de entrevistas semiestructuradas. La Observación Participante (OP) se llevó a cabo en cuatro sesiones, las cuales correspondieron a encuentros comunitarios donde la producción local del territorio se encontraba en el centro de la actividad. Las dos primeras se desarrollaron en la comunidad de Lirima (octubre 2011); OP I) "vigilancia de los animales en los humedales" y OP II) "once comunitaria" ${ }^{3}$ en dependencias de la empresa de exploración geotérmica. Las otras dos actividades se desarrollaron en la comunidad de Cancosa (enero-febrero 2012); OP III) "floreo de animales" ${ }^{4}$ y OP IV) el “ JACH'A ANATA" ". El objetivo principal de estas observaciones fue de identificar, desde "dentro" de las comunidades (Guber R., 2001:50), los significados sociales que sus miembros producían respecto de sus territorios, así como también, de recopilar información general de éstas. En este sentido, Filstead (1986) propone que los significados sociales "sólo pueden ser examinados en el contexto de la interacción de los individuos" (citado en Anguera M., 1997:73). En términos prácticos, en cada una de estas actividades se estableció un registro, entendido como una transcripción de las realidades observadas (Anguera M., et al., 1993), el cual fue posteriormente codificado temporal y espacialmente, con el objetivo de reconstruir socialmente los territorios comunitarios o territorialidades (información utilizada en la elaboración de las cartografías multitemporales).

Por otro lado, se aplicaron entrevistas semiestructuradas, entendidas por Spradley (1979:9) como "una estrategia para hacer que la gente hable sobre lo que sabe, piensa y cree" (citado en Guber R., 2001:75), a dirigentes y actores claves $^{6}$ de ambas comunidades, a miembros de la administración de escala local (Comuna de Pica) y a académicos especialistas de la región $(\mathrm{N}=11)$. Por razones de resguardo de la identidad de las personas entrevistadas, sus nombres fueron omitidos, tratándolos en el texto como "Informantes". De esta manera, y aun cuando se utilizaron las 11 entrevistas en la elaboración de las cartografías multitemporales, se citan textualmente sólo a seis informantes:

Informante 1; comunero de Lirima, 65 años.

Informante 2; comunera de Lirima, 73 años, habitante de la ciudad de Iquique Informante 3; funcionario municipal, Pica, 31 años.

Informante 4; comunera de Cancosa, 25 años, habitante de la ciudad de Iquique Informante 5; comunero de Cancosa, 76 años.

Informante 6; comunero de Cancosa, 32 años.

16 Establecida previamente una cronología local desde las fuentes secundarias, las entrevistas se concentraron en conocer la dinámica de la relación de los entrevistados con los territorios comunitarios y las actividades modernas (minería y turismo). Las preguntas estuvieron guiadas por tres temáticas; territorio (¿cuál es el territorio de la 
comunidad?, ¿cómo lo entienden?, ¿cómo lo usan?, ¿qué cambios ha notado en su medioambiente?), comunidad (¿cuáles han sido los cambios más importantes que ha vivido la comunidad durante su vida?, ¿han cambiado las relaciones comunitarias?, ¿cómo?) y actividad socioeconómica (¿cuál (es) es (son) las actividades económicas más importante (s) de la comunidad?, ¿han ido cambiando?, ¿cómo?). Estas preguntas de base se fueron adaptando según cómo fue evolucionando el relato de los entrevistados y el contexto de las entrevistas.

17 Una vez aplicadas las entrevistas, se procedió al estudio de la información mediante el análisis sociológico de los discursos ${ }^{7}$. Sobre la base de Ruiz (2009), quien propone establecer las conexiones entre los discursos, el contexto social y el espacio geográfico en el que surgen, se estableció un sistema de categorías espaciotemporales que busca caracterizar las "historias de vida" de las comunidades. De esta forma se establecen dos categorías de análisis (según dos de las tres temporalidades propuestas por Braudel, 1974, citado en Borrera, 2012:29 y Prado L., 2012:2); la categoría de "proceso social", comprendida como la temporalidad de los procesos sociales y políticos (en el caso de nuestro estudio, el tiempo de existencia de las comunidades) y la categoría de "proceso coyuntural", comprendida como la temporalidad del trabajo, los conflictos, solidaridad y movilidad en la vida cotidiana (en el caso de nuestro estudio, las últimas tres décadas).

Finalmente, y sobre la base de la información recolectada mediante Observación Participante y las categorías de análisis de los discursos de las entrevistas, se elaboraron cartografías multitemporales de dos momentos de las trayectorias de los territorios hidrosociales (figuras 4A-B y 5A-B).

\section{Geografía de la variabilidad socioambiental en Tarapacá; entre la adaptabilidad y el conflicto}

\section{Características hidroclimáticas de Tarapacá, presente y pasado de una condición dinámica}

Situada en el extremo norte de Chile, entre los $19^{\circ}$ y los $21^{\circ}$ Lat. Sur, la región de Tarapacá se encuentra en pleno centro de la zona considerada como la más seca del planeta: el desierto de Atacama (figura $\mathrm{N}^{\circ} 1$ ). En términos pluviométricos, las precipitaciones de la región se registran principalmente sobre los 3.000 m.s.n.m., se concentran casi exclusivamente en los meses de verano: diciembre-marzo (Garreaud R., et al., 2003) y presentan una alta variabilidad en sus montos interanuales (Sarricolea P. y H. Romero, 2015). Asimismo, Tarapacá registra una menor cantidad de días de precipitación y los montos de estas son menores que las regiones vecinas, así como también, la ocurrencia frecuente de varios años seguidos de sequías (Sarricolea P., et al., 2017).

La confluencia de los sistemas de circulación atmosférica de escala continental, regional y local (con sus campos de presión asociados), las temperaturas oceánicas del Pacífico y la topografía regional y subcontinental configuran un clima de extrema variabilidad (Romero H., et al., 2012; Sarricolea P. y H. Romero, 2015). En términos resumidos, Romero et al. (2013) y Mendonça (2017) indican que las fluctuaciones en los montos de precipitación estarían explicadas por la presencia e interacción compleja de 
fenómenos multiescalares como los son El Niño Oscilación del Sur (ENSO), la Oscilación Decadal del Pacífico (PDO) y la Zona de Convergencia Intertropical (ZCIT), entre otras. La condición sinóptica que propicia el desarrollo de las precipitaciones más frecuentemente en la región se presenta cuando la Alta Presión de Bolivia -célula de convergencia de flujos de aire que se ubica a gran altura- se intensifica, permitiendo que masas de aire húmedo, provenientes desde la cuenca amazónica y desde el Chaco, lleguen hasta las zonas altas del altiplano chileno. La presencia de células convectivas aumenta durante los periodos en que se presenta el fenómeno de La Niña y disminuye en presencia de El Niño (Nester P., et al., 2007; Mendonça M., 2017).

De esta forma, y bajo las condiciones hidroclimáticas actuales, el escurrimiento superficial es exiguo y se presenta sólo en los valles y quebradas que se encuentran en la mitad norte de la región, así como también en pequeñas lagunas y vertientes altoandinas (Aceituno P., 1996; Romero H., et al., 2013). Respecto al escurrimiento superficial de las aguas de la zona altoandina, Ahumada y Faúndez (2009) indican que en la mayor parte de las vertientes altiplánicas se clasifica como "azonal", es decir que no se explicaría por las condiciones climáticas presentes en la región, sino por la existencia y profundidad del acuífero, la actividad geotérmica, el tipo de suelo y la pendiente. En términos generales, las napas subterráneas presentes en la región se consideran como "acuíferos fósiles", es decir que sus cuerpos de agua fueron acumulados en periodos climáticos más húmedos que los actuales y sus recargas (esporádicas, semipermanentes y permanentes) no son suficientes para mantener su equilibrio hídrico, transformándolos en un recurso no renovable de alta fragilidad (Messerli B., et al., 1997; JICA, 1995; Houston J., 2006; Romero H., et al., 2012a y 2013).

Figura 1 Contexto geográfico de la región de Tarapacá

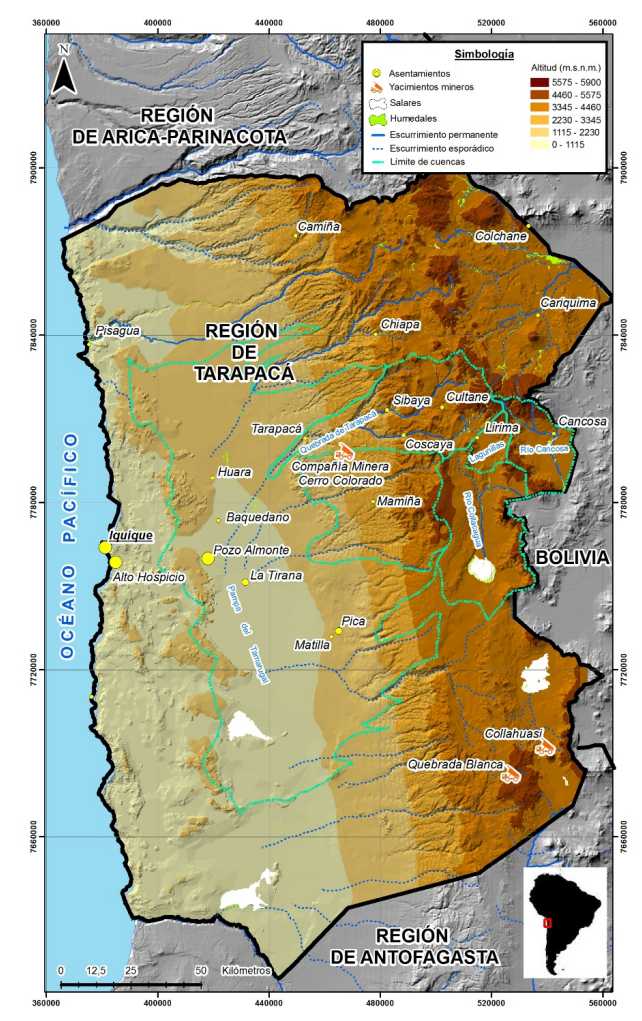

Fuente: Elaboración propia. 
una perspectiva paleoclimática, la región de Tarapacá ha mantenido su condición de hiperaridez durante los últimos 12.000 años Antes del Presente (Gayó E., et al., 2012a). Pese a estas condiciones generales, registros paleoclimáticos de menor escala temporal han puesto en evidencia numerosos episodios de "anomalías hidroclimáticas positivas", los cuales se presentaron durante todo el periodo Holoceno (Lehmann S., 2013; Amudson R., et al, 2012; Gayó E., et al., 2012a y b; Jordan T., et al., 2014). Estas "anomalías" se caracterizan por registrar mayores sumas promedio de precipitación en los sectores altoandinos y prolongarse desde unos pocos años hasta algunas décadas.

23 milenios, han sido interrumpidas por periodos cortos de mayor precipitación en las zonas cordilleranas. Estos escenarios ambientales de sequedad extrema impusieron grandes dificultades a las poblaciones ancestrales para su habitabilidad y circulación por los territorios regionales. No obstante, mediante el surgimiento de complejos mecanismos socioambientales de adaptabilidad, la región presenta trazas de una habitabilidad permanente durante al menos 12.000 años AP (Santoro C., et al., 2017).

\section{La producción de territorios multisituados como mecanismo de adaptabilidad socioambiental}

Sin adoptar una perspectiva de determinismo ambiental, es preciso indicar que las condiciones hidroclimáticas y topográficas particulares de la región de Tarapacá alcanzan una alta relevancia en la producción espaciotemporal de los territorios hidrosociales. En este sentido, importantes investigaciones arqueológicas y paleoclimáticas señalan que la disponibilidad de agua tuvo un rol esencial en los procesos de desarrollo cultural y construcción territorial de la región. De esta forma, Núñez et al. (2010) proponen que el agua es el elemento más importante a la hora de comprender los cambios socioambientales de la región, ubicada en pleno desierto de Atacama. Por otro lado, Santoro, et al., (2017) y Gayo, et al., (2012b) establecen una estrecha relación entre los periodos de anomalías hidroclimáticas positivas (asociados a una mayor disponibilidad de servicios ecosistémicos: agua, vegetación ripariana y fauna) y el desarrollo de estrategias socioculturales y espaciales para aprovechar estos periodos de abundancia relativa de recursos. Asimismo, Marquet, et al., (2012) plantean que la ocupación humana de las quebradas y costa de Tarapacá se relaciona directamente con los episodios de anomalías hidroclimáticas positivas.

Se evidencian de esta manera, complejos mecanismos a través de los cuales los grupos sociales prehispánicos modificaban sus patrones ocupacionales y socioeconómicos teniendo en cuenta la disponibilidad y abundancia de agua, vegetación y fauna, al mismo tiempo que intervenían microlocalmente la disponibilidad de estos elementos. Sobre la base de esta evidencia, se interpreta que estos mecanismos de adaptabilidad socioambiental (sensu Walker B., et al., 2004) producían diferentes territorios hidrosociales. Así, la producción territorial regional estaba constituida por pequeños territorios hidrosociales locales (muchos de ellos independientes políticamente), ubicados en diferentes altitudes y condiciones topoclimáticas (exposición, topografía local, posición en la cuenca), que favorecían una producción agrícola particular y una permanente dinámica socioambiental.

26 Algunos de los principales mecanismos de adaptabilidad socioambiental que producían diferentes territorios hidrosociales en la región durante el periodo prehispánico eran: 
la migración hacia zonas con mayor presencia de agua superficial (según Ledru M.P., et al., 2013; localizados a una altura mayor a 3700 m.s.n.m.); la concentración de la habitación en "refugios ecológicos", definidos como lugares puntuales con presencia de agua superficial permanente (Núñez L., 1986); la diversificación y amplificación, con fines de intercambio y/o guarda, de la producción agrícola y pastoril (Zori C. y E. Brant, 2012); el manejo simultáneo de diferentes topoclimas y recursos situados en pisos altitudinales distintos y en diferentes periodicidades estacionales basadas en una división y organización multi territorial de la producción, además de la especialización de tareas y movilidad de la fuerza de trabajo entre el altiplano, los valles, la pampa y la costa (Murra J., 1972; Van Kessel J., 2003). De igual manera, se desarrollaron tecnologías socioculturales complejas e intercambio político, económico y cultural, que, en el caso de la gestión de los recursos hídricos, implicaba "sofisticadas tecnologías de manejo de agua superficial, que incluian la construcción de pequeñas represas, canales de regadío, zonas de cultivo irrigado y el manejo de especies salvajes" (Santoro, et al., 2017:34). En este mismo contexto, Van Kessel (2003) y Zori y Brant (2012) interpretan el surgimiento y uso de determinadas terrazas de cultivo y canales de regadío como una adaptabilidad socioambiental, debido a la menor disponibilidad de agua. De igual manera, la necesidad de mayor seguridad alimentaria por el aumento demográfico y un clima social regional beligerante implicaba el uso de rocas para almacenar calor durante el día y generar micro-perturbaciones en las madrugadas para evitar las heladas. En el caso específico de la quebrada de Tarapacá, los asentamientos se desplazaban aguas arriba en periodos de escaso escurrimiento superficial y aguas abajo, incluyendo la Pampa del Tamarugal, cuando las precipitaciones eran abundantes, adaptando a su vez, las técnicas de riego y los productos cultivados a las diferentes características topográficas y de suelo.

Pese a que los grupos sociales prehispánicos desarrollaron un sinnúmero de mecanismos de adaptabilidad socioambiental, la gran variabilidad hidroclimática regional impedía que alguna de estas estrategias, por sí sola, les brindara una seguridad alimentaria (Barnard H. y A. Dooley, 2017). Ante este escenario, estas comunidades recurrían a una combinación compleja de decisiones que les permitiera asegurar su permanencia como grupo social. En consecuencia, la región se fue configurando a través de la producción articulada de una red de territorios multisituados ${ }^{8}$ (Girault, 2013; Méndez M. y H. Romero, 2018), generando condiciones hidrosociales que les permitía adaptarse a la elevada incertidumbre en la disponibilidad de agua, su control político y su uso y manejo a escala de cuencas y subcuencas. Asimismo, estos territorios multisituados no poseían una continuidad espacial, ni homogeneidad sociocultural, ni menos aún límites estables y claramente definidos, como propone Elden, 2010 para los territorios modernos, sino más bien una ecología política altamente dinámica (Boelens R., 2014).

\section{La modernización de Tarapacá y los conflictos por el territorio y el agua}

Méndez y Romero (2018) proponen que la modernización de los territorios de Tarapacá ha sido un proceso geo-histórico complejo que comienza con las primeras decisiones administrativas coloniales (ver figura $\mathrm{N}^{\circ} 2$ ). La imposición de los límites del corregimiento de Arica en 1578 (que incluía la actual región de Tarapacá) implicó la introducción de una concepción occidental del territorio, la cual debilitó las 
interacciones entre los territorios multisituados preexistentes, disminuyendo el intercambio cultural, económico y ritual entre las cabeceras de las colonias (ubicadas en el sector boliviano) y los territorios situados en las quebradas tarapaqueñas.

Adicionalmente, el nuevo Estado colonial introduce las denominadas "Cédulas Reales", las cuales reforzaron el concepto occidental de límite (como una línea fija establecida bajo parámetros objetivos), hecho que provocó la aparición de los primeros conflictos por el uso del territorio incluyendo las tierras agrícolas, las aguas y los humedales, entre otros. El primer conflicto territorial registrado en la región de Tarapacá se produce en 1612 (Paz Soldán M., 1878). No obstante, en este estudio centraremos nuestra atención en el primer conflicto por el uso y acceso de un humedal altoandino ${ }^{10}$.

Figura 2 Cronología de la producción territorial regional.

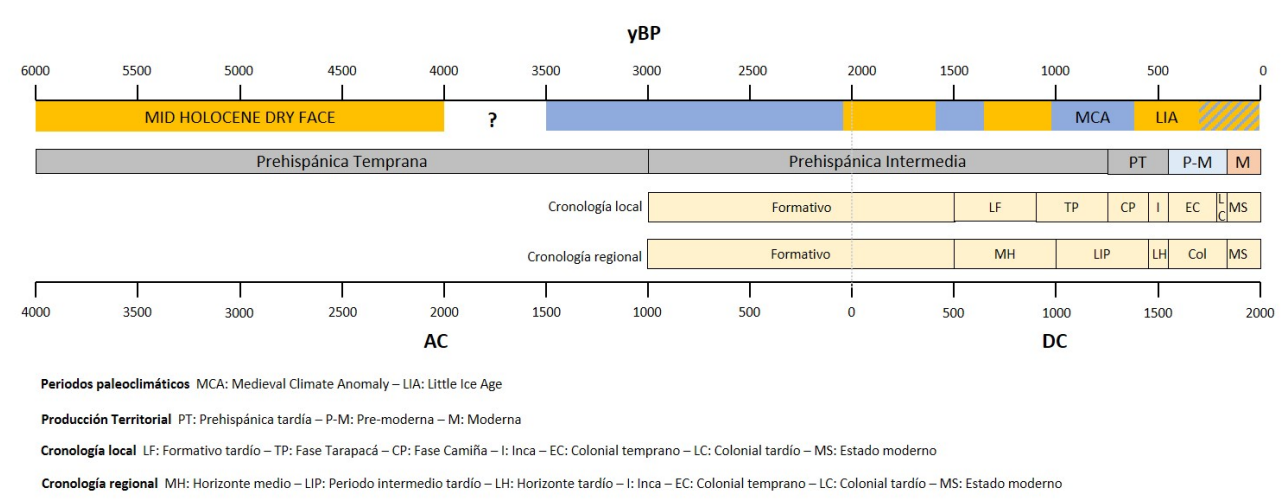

Fuente: Elaboración propia sobre la base de Méndez y Romero, 2018; Uribe, et al., 2007 y Santoro, et al., 2017

En 1768, tras la implantación de los límites de los corregimientos de Tarapacá, Lípez y Carangas en el altiplano tarapaqueño, la comunidad de Llica, cuyo pueblo principal se sitúa actualmente en territorio boliviano, quedó sin acceso a los humedales que tenía ubicados en las cercanías del cerro Sillajhuay (ver figura $\mathrm{N}^{\circ} 3$ ), los cuales contaban con abundante agua y hierbas. Tras este proceso administrativo, la comunidad se vio forzada a pagar un "derecho de herbaje" a la comunidad de Pica (que había quedado como dueña de este sector) (Paz Soldán M., 1878; Sanhueza C., 2008; Bouysse-Cassagne T. y J. Chacama, 2012). El desencuentro se produce cuando la comunidad de Llica interpreta esta apropiación como injusta, dejando de pagar este canon por el acceso a un territorio que, bajo los arreglos de uso ancestral, siempre dispuso libremente. Estos conflictos se fortalecieron entre 1810 y 1840 , llegando incluso a que la comunidad de Llica "invadiera" y destruyera, entre otras localidades, la hacienda de Cancosa (Paz Soldán M., 1878:32-34).

31 Aun cuando estas disputas fueron puntuales y se produjeron "entre" las comunidades y no "al interior" de ellas, donde continuó funcionando la construcción territorial ancestral ${ }^{11}$, en términos prácticos los conflictos causados por la superposición del ejercicio territorial bajo los usos y costumbres andinas y los deslindes privados coloniales marcan el inicio de la imposición occidental del concepto de territorio (Méndez M. y H. Romero, 2018).

En el caso del agua, la imposición de los territorios hidrosociales modernos es menos evidente, pues no existen registros históricos de conflictos directos por su uso y/o acceso hasta la llegada del Estado chileno. Sin embargo, se propone que uno de los 
primeros indicios de la imposición conceptual del "agua moderna" (sensu Linton J., 2010) se produce a través del proyecto hidráulico propuesto por Antonio O'Brien durante la segunda mitad del siglo xviII. Empujado por la crisis económica de la corona española, O'Brien realiza en 1765 un estudio del mineral de Huantajaya (ubicado en las cercanías de Iquique), llegando a la conclusión de que la escasa rentabilidad del yacimiento se explicaba por la falta de agua (Donoso C., 2008) ${ }^{12}$. Tras esta conclusión, O'Brien propone un proyecto hidráulico que buscaba captar las aguas desde las nacientes del río Piga, para luego canalizarla y de otras fuentes en la cuenca de Lagunillas y la cuenca alta de la Quebrada de Tarapacá (además de captar aguas de las lagunas de Chuncara, situadas fuera de la zona de estudio), para abastecer la denominada Pampa Iluga, que es la proyección de la Quebrada de Tarapacá en la Pampa del Tamarugal. El foco del proyecto era poner a disposición de la actividad minera una mayor cantidad de recursos hídricos para su procesamiento y para generar una gran zona de actividad agrícola que abasteciera de alimentos al mismo yacimiento (Hidalgo J., 1985).

33 Posteriormente, y junto con la llegada de los Estados modernos a Tarapacá, otro elemento de transformación discursiva y material de la construcción territorial hidrosocial de la región fue la explotación industrial del salitre, entre fines del siglo XIX y comienzos del xx. Esta industria se encontraba instalada en las zonas más bajas (y secas) de la Pampa del Tamarugal. Durante las primeras décadas de explotación mineral, el agua era extraída de pozos ubicados junto a los yacimientos traída desde las “aguadas" más cercanas (Méndez M., 2019). Posteriormente, entre las décadas de 1850-1870, la inserción del salitre tarapaqueño en los circuitos capitalistas mundiales marca un gran salto en el número de explotaciones y los volúmenes de nitrato extraídos (Bermúdez O., 1963). Este incremento productivo empujó a los capitalistas a considerar las aguas como un elemento de especulación económica más del territorio salitrero (Godoy M. y M. Méndez, 2018). De esta manera, la independencia espacial que la tecnología de bombas y el uso de cañerías les brindaba a los industriales salitreros les permitió extraer aguas subterráneas cada vez más cerca de las quebradas y de los asentamientos ancestrales de la Pampa del Tamarugal (Méndez M., 2019). En este contexto de competencia por el recurso, se produce el primer conflicto moderno por el agua, entre el Estado de Chile y la comunidad indígena del valle de Quisma ${ }^{13}$ (situado inmediatamente al este de la actual localidad de Matilla, ver figura $\mathrm{N}^{\circ} 1$ ). Este conflicto terminó con la expropiación de las tierras y las aguas del valle y la expulsión de la comunidad de este territorio agrícola ancestral (Castro L., 2010).

Otro aspecto de modificación de la producción territorial regional (y sus condiciones hidrosociales particulares) fue la introducción obligatoria de la educación formal (Méndez M., y H. Romero, 2018). Posterior a la Guerra del Pacífico ${ }^{14}$, el Estado chileno refuerza la concentración de la población a través de la instalación de "poblados centrales". Aun cuando este fue un instrumento de control territorial impuesto durante la colonia, se ve intensificado en Tarapacá durante el proceso de chilenización ${ }^{15}$. En este último periodo, el Estado obliga a las comunidades locales a recibir una educación occidental (lengua, costumbres, expectativas de vida, ropa, comida, etc.), obligándolas a agruparse espacialmente para tener acceso a los "servicios" estatales. Respecto a este periodo el Informante 1 recuerda:

“Inclinarse por la tradición del abuelo, de la mamá... mostrar cierto interés era implícitamente prepararme el camino p'al infierno...y que voy a querer un castigo po... ¿quién va a querer eso?" 
En este contexto, González (2002), propone que las comunidades indígenas no fueron "actores pasivos" del proceso, pues eran estas mismas quienes solicitaban al Estado la instalación de escuelas en sus poblados, llegando incluso a contratar profesores particulares. Esta propuesta es coincidente con diversas entrevistas realizadas por los autores en diferentes localidades del altiplano de Arica-Parinacota y Tarapacá, en el sentido que los habitantes altoandinos identifican la educación como el único medio de "escapar" de la exclusión y marginalidad asociadas a su realidad cotidiana. En consecuencia, se puede aseverar que los habitantes habían incorporado (cooptados o no) ${ }^{16}$ en su discurso y su acción, lo que Gundermann (1986) (en González S., 2002) denomina el estereotipo del progreso y el desarrollo.

Durante los primeros años de la inserción de las escuelas en el altiplano tarapaqueño, las comunidades mantenían su territorialidad dispersa. Así se puede rescatar desde el relato de Ornaldo Bacián Callpa, profesor que estuvo a cargo de la escuela primaria $\mathrm{N}^{\circ} 18$ de Cancosa desde 1959, quien asevera:

"En la escuela yo tenía unos 22 chiquillos y el poblado [la comunidad] tendría unas 15 familias... ése era un pueblo de pastores, no tienen su residencia permanente allí en Cancosa se juntaban los vecinos algunas veces no más en el año, cuando hay fiestas religiosas, el carnaval, en mayo, el año nuevo, pero después se iban a los cerros, a los lugares de pastoreo..." (González 2002:133).

No obstante, y según el relato de los Informante 1 y 5, a medida que los escolares avanzaban en sus currículums, la solución más recurrentemente adoptada por las familias andinas fue el desplazar su habitación permanente hacia las ciudades o localidades que contaban con educación media y universitaria. Otra estrategia utilizada, extraída del relato del Informante 4, fue que la madre de familia "bajaba" para estar con los jóvenes durante el periodo escolar, para posteriormente volver a la comunidad en vacaciones. Pese a que algunas familias se esforzaron por mantener viva la tradición territorial, a medida que los niños se transformaron en jóvenes, fueron haciendo menos recurrentes sus "subidas" a la comunidad originaria.

Las principales consecuencias registradas por los autores fueron dos. Por un lado, las primeras generaciones de jóvenes aymaras con educación occidental jugaron un rol importante en el proceso de cambio cultural. En este sentido el Informante 1 indica:

"En estas escuelas se les preparaba para vivir en la ciudad, les daban comida traída desde Iquique, cuando llegaban a casa [los niños] se enojaban con las mamás y papás por cómo vestían y porque hablaban aymara."

Estos primeros "ciudadanos andinos" se convirtieron en agentes de cambio cultural en el seno de sus propias familias, donde fueron reproduciendo su educación occidental. Por otro lado, al habitar en otros territorios, las nuevas generaciones dejan de aprender y aplicar su cultura cotidiana de construcción territorial; ya no conocen los ciclos de la naturaleza, desconocen el nombre de cerros o plantas, o han perdido la capacidad de reconocer los estados de los animales, ya no recorren los circuitos de pastoreo. Las nuevas generaciones no estaban pensando en recuperar las variedades de quinua, o en el cuidado de los animales, o los sistemas de cultivos de papa, entre otros. Desde una visión contemporánea, la Informante 4 nos resume de forma bastante elocuente:

"mi forma de vida está hecha acá [ciudad de Iquique], solo que esporádicamente subo [a la comunidad altoandina]... no es que yo vaya a ser mi vida arriba, es super difícil, por el tema que uno después prefiere tener hijos, quiere tener familia, después tú quieres que ellos tengan una mejor educación o mayores aspiraciones... 
no hay mucho de la generación que quiera sacrificar esta comodidad [vivir en la ciudad] para irse para allá."

\section{Producción de territorios neoliberales: estudio de los conflictos entre las comunidades de Lirima y Cancosa.}

Lirima y Cancosa son dos comunidades de etnia aymara, las cuales se formaron a principios del siglo xx y se constituyeron como "comunidades indígenas" de acuerdo con la Ley dictada en 1993 para proteger sus culturas y territorios. Desde sus inicios, hasta la década de los años 1980's, ambas comunidades se dedicaban principalmente a la ganadería extensiva de camélidos, lo cual comienza a cambiar con la llegada de empresas trasnacionales de la gran minería del cobre, las cuales se interesan por la disponibilidad de agua que poseen estos territorios altoandinos. La introducción de este nuevo actor provocó la reconversión de estas comunidades hacia los servicios mineros, en el caso de Lirima, y del turismo, en el caso de Cancosa.

41 Bajo la dictadura del general Pinochet (1973-1990), se consolidan los procesos de privatización de recursos públicos y comunitarios en todo el país, incluyendo el derecho de uso privado de las aguas con fines económicos que se estableció a contar de 1981. Las exploraciones hidrogeológicas y la inscripción, por parte de empresas externas de derechos de uso de agua adquiridos entre otros actores a las comunidades indígenas, desató una álgida disputa por los recursos hídricos almacenados en la laguna del predio Huantija y pos sus territorios adyacentes.

\section{Comunidad de Lirima}

La comunidad de Lirima se encuentra ubicada en la comuna de Pica, específicamente en la cuenca superior de la Quebrada de Tarapacá y en la cuenca endorreica de Lagunillas (ver figura $\mathrm{N}^{\circ} 3$ ). Su poblado central (Lirima) se encuentra a 4.087 m.s.n.m. y al año 2002 registraba una población permanente de seis personas. Sus principales actividades económicas eran los servicios mineros y la ganadería extensiva. 
Figura 3 Comunidades de Lirima y Cancosa.

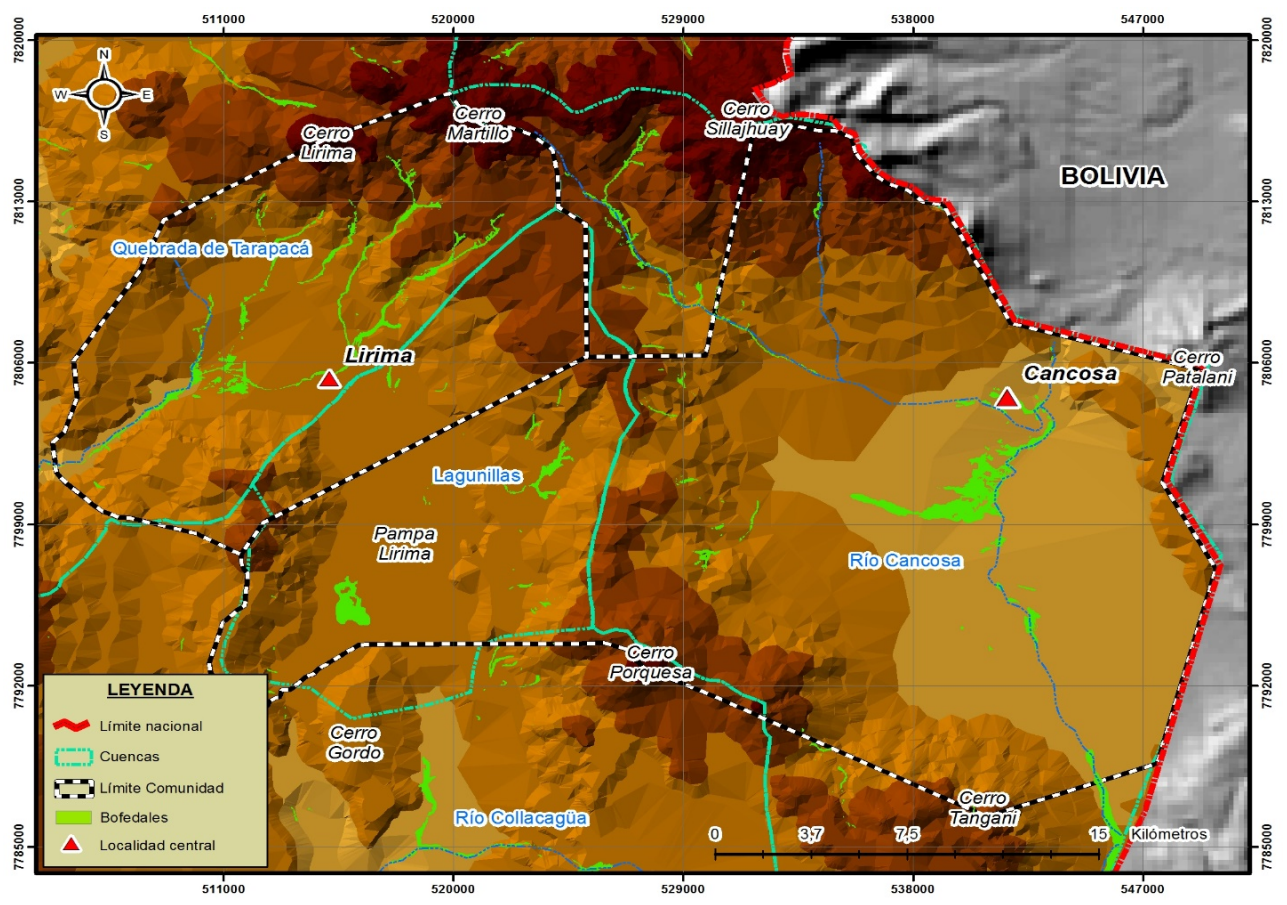

Fuente: Elaboración propia Iquique o Alto Hospicio) trabajan en la planta de extracción y conducción de aguas desde Pampa Lirima hacia el yacimiento de cobre de la Compañía Minera Cerro Colorado (CMCC), así como también, hay algunos comuneros que prestan servicios en el 
yacimiento mismo (OP II). Otra de las fuentes de empleo de los "comuneros citadinos" es la empresa geotérmica Energía Andina, la cual llega al territorio de Lirima en el año 2008. Tras una discusión interna, la comunidad aprueba la instalación de la empresa y por este acuerdo, presta el servicio de alimentación, aseo y mantenimiento al campamento de la compañía (OP II). En este sentido, el Informante 1 señala que, si ellos no llegaban a acuerdo con la empresa de energía, sería el tribunal quien dictaría la intervención, obligando a entregar una servidumbre de paso para el aprovechamiento del subsuelo.

\section{Comunidad de Cancosa}

Cancosa es una comunidad aymara que se localiza en la comuna de Pica, sobre las cuencas del río Cancosa y la cuenca de Lagunillas. El poblado principal de la comunidad se ubica a 3.950 m.s.n.m (ver figura $\mathrm{N}^{\circ} 3$ ) y al año 2012 contaba con 12 habitantes permanentes. Su principal actividad es la ganadería extensiva, la cual es complementada con el cultivo de quinua y una creciente actividad turística.

La comunidad de Cancosa se funda alrededor de 1920 por cuatro familias, las cuales provenían desde los alrededores de la localidad de Cariquima (Salinas J., 2012). El apogeo de la comunidad se vivió a inicios de la década de 1980's, periodo en el cual vivían alrededor de 200 personas, debido al gran tráfico de productos entre la Zona Franca de Iquique-Chile (ZOFRI) y la ciudad de Oruro en Bolivia, además de la extracción de azufre desde el cerro Sillajhuay, situado en las cercanías. En este periodo la localidad central contaba con una posta de salud rural, por lo que los comuneros no tenían la necesidad de ir a la ciudad. Estos años de "bonanza" terminan cuando se abre un nuevo paso internacional entre Chile y Bolivia por la localidad cercana de Colchane, a fines de la misma década.

49 Al año 2012, existían alrededor de 600 animales en la comunidad, la mayoría de los cuales eran corderos, llamas y alpacas. Respecto a la actividad ganadera, la Informante 4 señala que el cuidado de los corderos requiere de mayor trabajo, pues se deben sacar diariamente desde sus corrales; mientras que el cuidado de las alpacas demanda menos vigilancia, pues se pueden dejar solos en el humedal. En el caso de las llamas, que en épocas anteriores era el animal más importante en términos de volumen, los comuneros los van a ver sólo una vez por semana pues "hay que ir a buscarlo a los cerros". En la mayor parte de los casos este recorrido se realiza en vehículos, lo que ha originado una pérdida del uso de los senderos de pastoreo, así como la tradición misma de la actividad (OP IV). En este sentido, las familias que no se encuentran viviendo permanentemente en la comunidad "externalizan" el cuidado de estos, a través de familiares o la contratación de pastores bolivianos (OP IV).

50 Respecto a las condiciones actuales de la crianza de animales, el Informante 5 indica que los pastores han perdido varios animales por los ataques del puma, que incluso entra a los corrales, "el mes anterior [enero 2012] se comió 4 alpacas en un humedal que está junto al pueblo". Además, según la percepción de mismo informante, antes había más lluvia y más seguido, lo que afecta el crecimiento de los pastos de secano (cuando hay mucha sequía, los comuneros alimentan a sus animales con forraje comprado en los valles cercanos). En este mismo sentido, el Informante 6 señala que el número de animales ha disminuido por la sequía ("no llovió desde 2001 hasta el 2011") y debido a que hay una plaga de pumas. Asimismo, el relato del Informante 5 es clarificador 
respecto a los cambios de la actividad, pues en la actualidad sólo tiene alpacas; antes de bajar a la ciudad tenía llamas, pero ahora no las puede cuidar. Según lo que indica este pastor, todas las familias tienen derecho de tener sus animales en el humedal ubicado junto a Cancosa, como consecuencia de su propiedad comunitaria ${ }^{18}$. Finalmente, el mismo informante nos señala que en invierno mantienen los animales en el humedal, pues el agua continúa escurriendo (surgencias geotérmicas).

51 Según la Informante 4, los abuelos de la comunidad siguen criando animales en la medida que aún constituyen su sustento, vendiéndolos para la celebración de las fiestas patronales (religiosas) y fiestas de la independencia nacional, entre otras. Cada llama se vende entre 100.000 y 120.000 pesos chilenos (US\$120-150) y cada cordero entre 50.000 y 60.000 pesos chilenos (US\$60-80). Los animales se comercializan cuando tienen una edad de alrededor de 2 años y medio, ya que con posterioridad la carne pierde calidad y precio. Respecto a las alpacas, la Informante 4 indica que sólo quedan algunos abuelos que crían esta especie, pero que esta práctica se está abandonando.

\section{Territorio, minería y conflictos hidrosociales inter e intracomunitarios.}

Los conflictos hidrosociales entre las comunidades de Lirima y Cancosa con las empresas mineras comienzan por una solicitud de inscripción de derechos de agua superficial en los sectores de Lirima, Piga y Huantija por parte de la empresa Conocco Chile en 1981 (Van Kessel J., 1985). Según el relato del Informante 1, la comunidad de Lirima se entera fortuitamente por la prensa que, utilizando la nueva legislación de privatización de los derechos dictada ese mismo año, la empresa estaba realizando los procesos de inscripción de sus aguas superficiales. Tras una serie de maniobras institucionales, la comunidad presenta una oposición a la inscripción e impide la apropiación de estas, transformándose en la primera que se resiste al desarrollo de la actividad minera en su territorio.

En 1982 la empresa minera Río Chile comienza a hacer sondajes en los territorios de Lirima, los cuales fueron paralizados gracias a una acción legal interpuesta por la comunidad. Tras unos meses, la misma empresa inicia sondeos en Huantija (Pampa Lirima) con la autorización de la comunidad de Cancosa, quienes les arriendan terrenos y aguas superficiales (Van Kessel J., 1985). Según los relatos de Javier Vilca (citado en Van Kessel J., 1985), el predio de Huantija pertenecía a un comunero de Lirima, quien realizó una venta a su comunidad. No obstante, y con la ayuda de los abogados de la empresa minera, una comunera de Cancosa (ex esposa del dueño original del predio) presenta una demanda contra la comunidad de Lirima, juicio que estaba destinado a impedir la paralización de los trabajos ${ }^{19}$. Durante el transcurso del mismo año (1982), la Dirección General de Aguas (DGA) otorga 300 lt/seg. de derechos de agua subterránea en el sector de Huantija a la Compañía Minera Cerro Colorado (CMCC) (Salinas J., 2012).

En 1985 la empresa Sociedad Cobre Iquique Ltda., presenta una demanda por servidumbre de paso a la comunidad de Lirima (para la construcción de un camino y la instalación de un acueducto por sus terrenos). Aun cuando la comunidad intenta rechazar la solicitud, los artículos 120 del Código Minero y 76 del Código de Aguas (ambos cuerpos legales impuestos en periodo de dictadura), obligan a conceder esta servidumbre. Es así como la comunidad de Lirima llega a un acuerdo con la empresa, a través del cual la minera dotó de electricidad al poblado central y contrató a sus 
comuneros para mantener en funcionamiento la planta de extracción de agua de Pampa Lirima (Van Kessel J., 1985).

Superados los problemas intercomunitarios, en la década de los años 1990 se originan nuevos conflictos por la propiedad de tierras y agua, esta vez entre la CMCC y la comunidad de Cancosa, los que terminan a través de un acuerdo económico que, a juicio de los mismos comuneros, afectó severamente la harmonía interna de la comunidad.

En 1992 CMCC inicia sus faenas de extracción y procesamiento del mineral de cobre y en 1994 comienza la extracción de agua subterránea desde el predio Huantija (Salinas J., 2012). Según la Informante 4 , los problemas entre la minera y la comunidad comienzan a fines de la década de los años noventa, cuando esta última percibe el desecamiento de los humedales (bofedales), que están en torno a la laguna Lagunillas, así como también, el descenso del nivel de las aguas en este cuerpo. En 2006 la autoridad hídrica del Estado (Dirección General de Aguas, DGA) y la Comisión Nacional del Medio Ambiente (CONAMA, actual Ministerio del Medio Ambiente) sancionan económicamente a la compañía minera por el daño ambiental infringido al acuífero de Pampa Lirima, estableciendo un programa de restauración ecológica para estos humedales. Pese a que en el año 2006 los comuneros de Cancosa habían interpuesto acciones legales contra CMCC, la comunidad y la minera llegan a un acuerdo extrajudicial en 2008, válido por un plazo de 30 años, consistente en una compensación económica por el daño al humedal de Lagunillas y las medidas de recuperación de este bofedal. Los dineros correspondientes se entregan mensualmente a la comunidad, quienes no los asignan directamente a cada familia miembro, sino que financian una estructura administrativa comunitaria, proyectos de desarrollo y becas de estudios para los hijos de los comuneros.

En este mismo sentido, el Informante 5 indica que el acuerdo entre la comunidad y la empresa minera provocó profundas divisiones internas por causa del dinero que recibieron de CMCC, señalando que hoy en día no hay un interés real por la comunidad:

"los que se acercan a ella sólo buscan tener acceso a los recursos y no quieren trabajar la tierra."

Por su parte, el Informante 4 revela que los abuelos nunca pensaron que las acciones legales con que se opusieron a las instalaciones mineras iban a terminar generando una división con las nuevas generaciones de las familias fundadoras, las cuales intentan demostrar que poseen mejores derechos para recibir la compensación económica. En este mismo sentido, el Informante 4 indica que durante las asambleas de la comunidad surgen muchas disputas causadas por el acceso al poder y por los intereses personales, al mismo tiempo que se debilitan los intereses de la comunidad en su conjunto.

\section{Dinámica territorial hidrosocial de dos subcuencas altoandinas: desde la complejidad multisituada a la simplificación neoliberal}

59 De esta forma, sobre la base de información secundaria, de aquella recolectada a través de la observación participante y de las entrevistas, se propone una reconstitución de la construcción territorial de las comunidades de Lirima y Cancosa en dos momentos (figuras $\mathrm{N}^{\circ} 4 \mathrm{y} \mathrm{N}^{\circ} 5$ ). En el primero de ellos, plasmado en las cartografías de las figuras $\mathrm{N}^{\circ} 4 \mathrm{~A}$ y $\mathrm{N}^{\circ} 5 \mathrm{~A}$, se observa el funcionamiento de los territorios hidrosociales multisituados, cuyos principales elementos de producción territorial son la movilidad 
espacial (uso de circuito de pastoreo y transhumancia), el uso familia/comunidad de fuentes de agua y terrenos adyacentes (bofedales/praderas) y la habitabilidad dispersa (OP I, OP III y entrevistas). Se propone que esta producción territorial compleja es representativa del periodo comprendido entre la creación histórica y consuetudinaria de las comunidades (inicios del siglo xx) y la segunda mitad de la década de 1950, periodo en el cual se finaliza la construcción de la carretera Iquique-Oruro y se instala la escuela en Cancosa.

El segundo momento, que por defecto se extiende entre mediados de la década de 1950 y la actualidad (representadas en las cartografías $\mathrm{N}^{\circ} 4 \mathrm{~B}$ y $\mathrm{N}^{\circ} 5 \mathrm{~B}$ ), correspondería al periodo en el cual se va instalando paulatinamente la territorialidad occidental, es decir una comprensión del territorio y sus recursos como propiedad privada. Durante este periodo, la habitabilidad se concentra en los asentamientos centrales, con fines educacionales. Como consecuencia de este mismo proceso de inserción de las nuevas generaciones de las comunidades a la educación formal, las familias comienzan a migrar hacia las ciudades de la región, con el fin de que sus hijos puedan continuar sus estudios (OP II y entrevistas). Posteriormente, la instalación de la legislación neoliberal en la década de los 1980's transforma discursiva y materialmente a la naturaleza (agua y subsuelo) en un commodity, cuyos derechos de uso por parte de las empresas privadas implica compensaciones económicas a las comunidades, proceso que desencadena la pérdida de las relaciones cercanas de éstas con su entorno natural, con las comunidades vecinas y aún al interior de estas.

Figura 4 Cambios territoriales en la comunidad de Lirima.

A) Producción territorial hidrosocial multisituada.

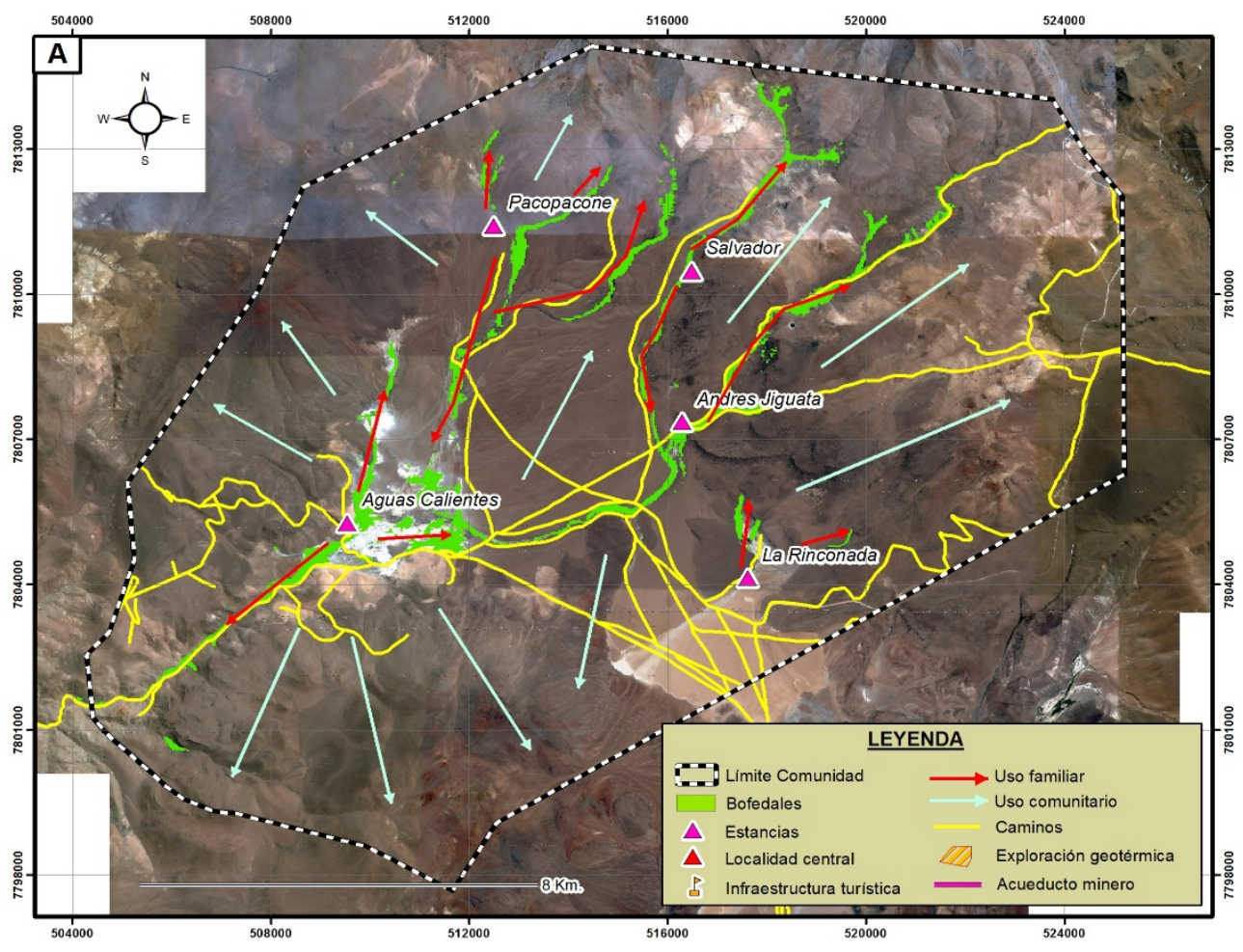


B) Producción territorial neoliberal.

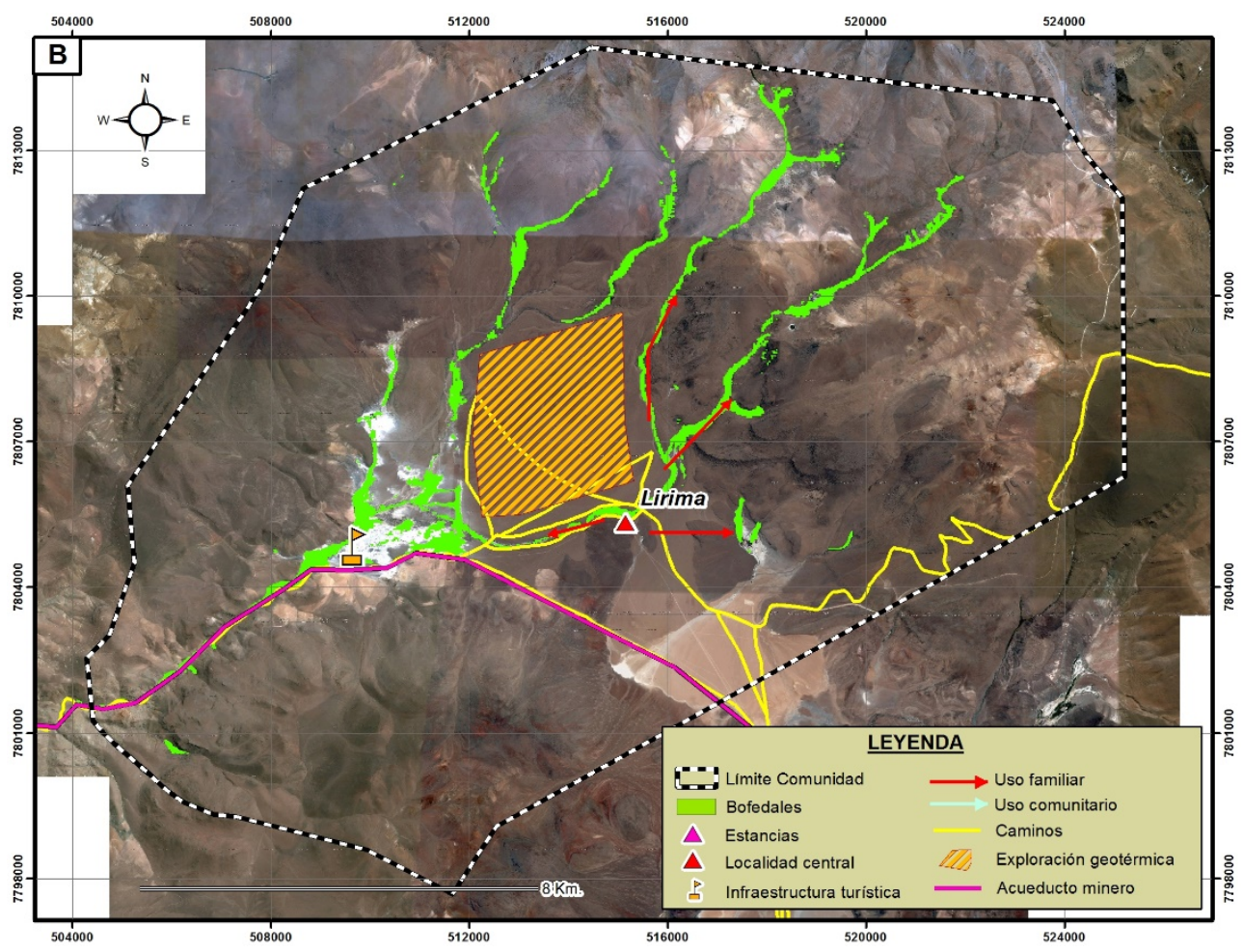

Fuente: Elaboración propia.

Figura 5 Cambios territoriales en la comunidad de Cancosa.

A) Producción territorial hidrosocial multisituada.

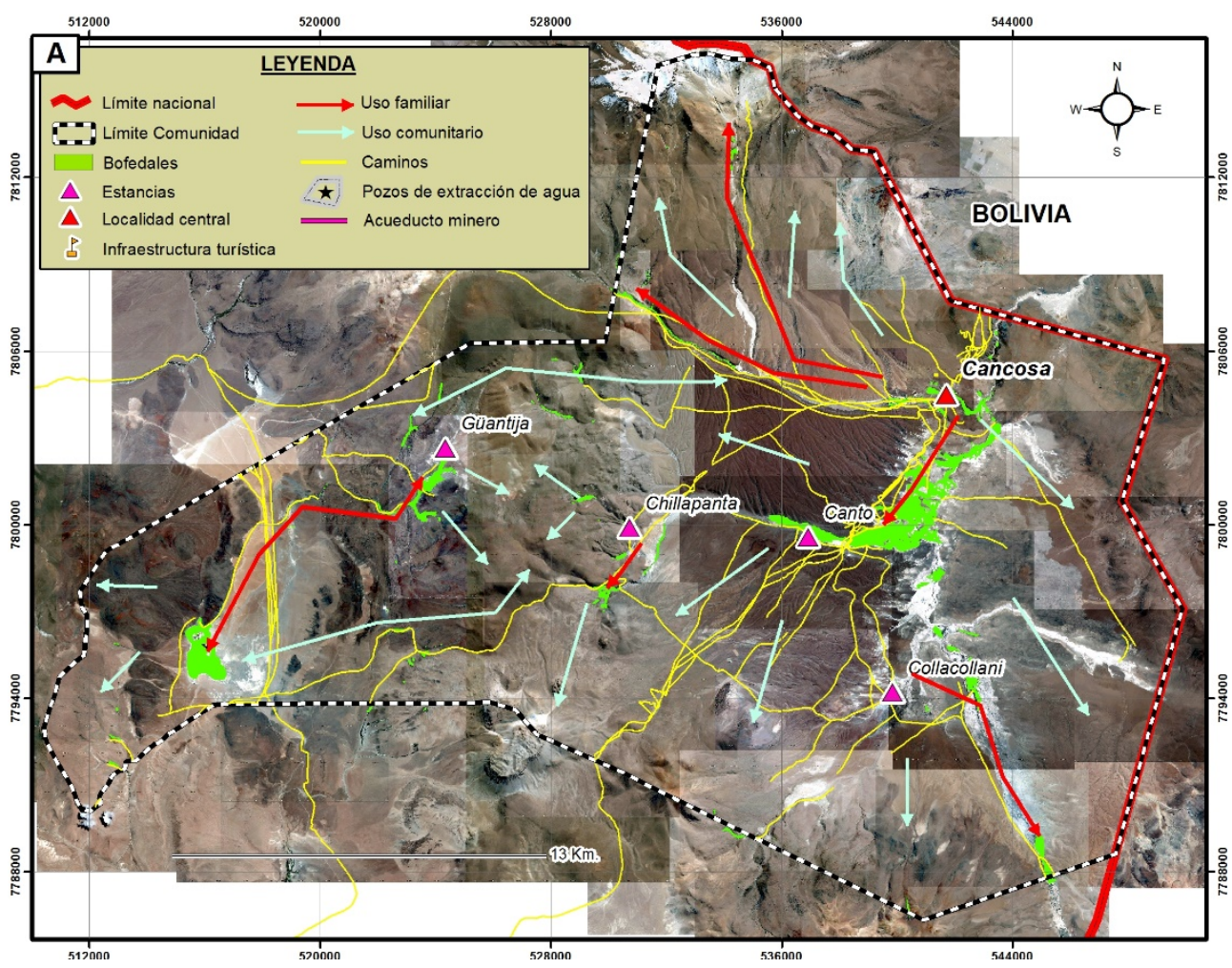

IdeAs, 15 | 2020 
B) Producción territorial neoliberal.

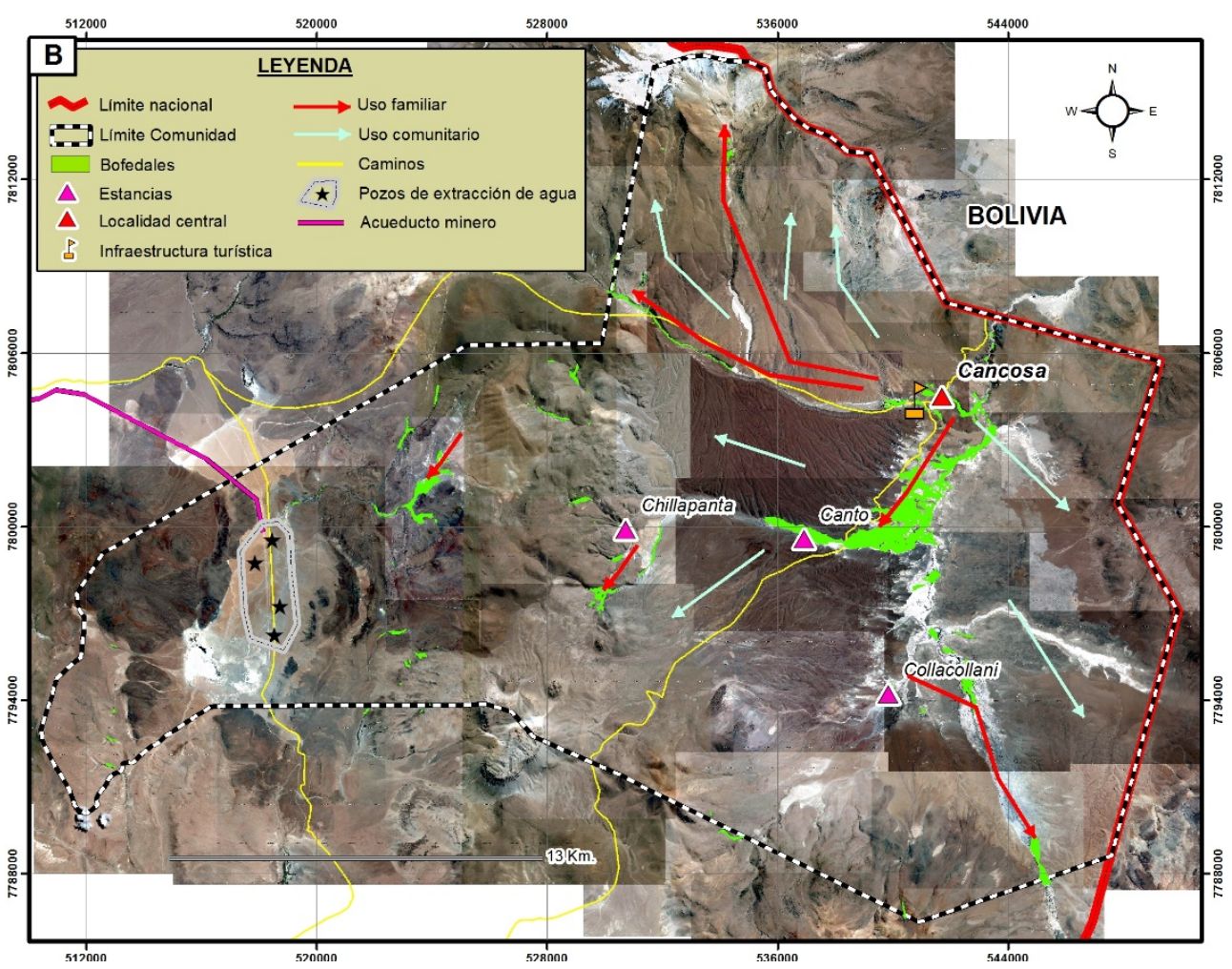

Fuente: Elaboración propia.

\section{Reflexiones finales}

Tanto los resultados de esta investigación, como otros estudios analizados, ponen en evidencia que los variados sistemas sociopolíticos que han ocupado los espacios altoandinos han producido diferentes configuraciones territoriales, siendo la modernidad colonial y los Estados republicanos el periodo de mayores cambios. Este complejo proceso de imposición de conceptos y prácticas coloniales que se produce en la región de Tarapacá, se va materializando lentamente a través del reconocimiento cooptado por parte de las comunidades, de las instituciones coloniales como entes que controlaban la toma de decisiones, las cuales instalan sus procedimientos administrativos en el seno del ejercicio del poder territorial (distribución y tenencia de la tierra y el agua), además de invisibilizar los conocimientos y procedimientos de gestión hidrosocial y territorial prehispánicos. De esta forma, se puede aseverar que las modificaciones en el funcionamiento cultural fueron erosionando paulatinamente la construcción territorial hidrosocial multisituada, para instalar en su lugar la habitabilidad centralizada y la concepción territorial moderna como elemento característico de los paisajes altiplánicos tarapaqueños.

Entre las principales consecuencias de este proceso se pueden mencionar: el severo despoblamiento de las zonas rurales, el desuso de las costumbres socioproductivas y los cambios en la construcción territorial. Respecto a este último aspecto, tanto el análisis de fuentes secundarias como el estudio de caso muestran un notable abandono de las costumbres ancestrales de producción territorial hidrosocial, provocando una 
simplificación, resignificación y desocupación de los espacios altoandinos, volviéndolos más permeables a la penetración de formas de capital más agresivo, como lo es la actividad minera de gran escala.

63 Asimismo, la legislación neoliberal sobre otorgamiento de derechos de uso del agua, impuesta desde 1981, permitió a las empresas tener acceso los recursos hídricos sin necesidad de disponer de tierra, o la explotación de las aguas subterráneas, aun cuando no fuesen propietarias de los terrenos superficiales. La separación de las aguas y las tierras, de las fuentes superficiales y las subterráneas, la obligación de aceptar servidumbres de paso a las empresas y la ausencia de una gestión integrada de cuencas que considerara la vinculación entre las secciones superiores, medias y bajas de estas, han constituido fuerzas directrices relevantes en la configuración territorial más reciente y en la generación de conflictos socioterritoriales permanentes.

De esta manera, los principales aportes de esta investigación son tres. Desde una perspectiva teórica, la adopción de un análisis geo-histórico, así como una comprensión dialéctica de las relaciones entre la sociedad y la naturaleza, permiten avanzar en el conocimiento de los profundos cambios hidrosociales y socioambientales experimentados por las comunidades altoandinas del Desierto de Atacama.

Con respecto a los territorios de Lirima y Cancosa, proponemos la existencia de tres territorios diferentes. La territorialidad de los adultos mayores, quienes son los únicos que viven permanentemente en los lugares y que mantienen, en la medida que su edad se los permite, la construcción andina ancestral. La territorialidad de los adultos de mediana edad, quienes viven en las ciudades, mantiene algunas actividades económicas ligadas a la territorialidad ancestral en las comunidades de origen, además de participar activamente en sus festividades y actividades ${ }^{20}$. La territorialidad de los jóvenes, quienes viven en la ciudad y se muestran escasamente interesados en la mantención de la construcción comunitaria. Respecto a este último segmento, se puede afirmar que, aun cuando hay un reconocimiento y de cierta manera un rescate de los aspectos valóricos de la cultura comunitaria ancestral, los aspectos materiales territoriales no poseen una continuidad en su generación.

66 Respecto a los procesos de conflictividad territorial, se observa que el periodo minero más reciente ha intentado reparar los daños ambientales causado por sus instalaciones y por el apoderamiento de los derechos de agua mediante el pago de compensaciones económicas a las comunidades, lo que ha aumentado las tensiones y conflictos, ahora no solo entre los inversores externos y las comunidades, sino que también entre los propios representantes comunitarios que pugnan por obtener una mayor participación en los beneficios personales sin que necesariamente se pretenda mantener a la comunidad de lugar.

67 Finalmente, la comparación de los dos momentos histórico-territoriales de las comunidades de Lirima y Cancosa (figuras $\mathrm{N}^{\circ} 4 \mathrm{~A}-\mathrm{B}$ y $\mathrm{N}^{\circ} 5 \mathrm{~A}-\mathrm{B}$ ) pone en evidencia la dilución paulatina de la propiedad común altoandina, marcando su punto culminante durante el proceso de comodificación del agua y el subsuelo del sector Lagunillas y Pampa Lirima. Respecto a este último punto, cabe destacar que la llegada de la actividad minera del cobre, y posteriormente la prospección geotérmica, no son los únicos elementos causantes de los cambios territoriales de estas comunidades, sino más bien, hitos cúlmines del proceso de modernización territorial, donde se alcanza la mayor simplificación de las relaciones territorio/sociedad/naturaleza. 


\section{BIBLIOGRAFÍA}

Aceituno, Patricio, «Elementos del clima en el altiplano sudamericano”. Revista Geofísica IPGH, $1996, \mathrm{n}^{\circ} 44$, p. 37-55.

Aedo, Juan, « Percepción del espacio y apropiación del territorio entre los aymara de Isluga ». Revista Estudios Atacameños, 2008, n 36, p. 117-137.

Ahumada, Mario y Faúndez, Luis, Guía descriptiva de los Sistemas Vegetacionales Azonales Hídricos Terrestres de la Ecoregión Altiplánica (SVAHT), Santiago, Servicio Agrícola y Ganadero de Chile (SAG), 2009.

Aliste, Enrique, « Territorio y ciencias sociales: Trayectorias espaciales y ambientales en debate » En: Aliste, Enrique y Urquiza, Anahí. (compiladores), Medio ambiente y sociedad: conceptos, metodologías y experiencias desde las ciencias sociales y humanas, Santiago, RIL editores, 2010, p. 55-76.

Amudson, Ronald, Dietrich, William, Bellugi, Dino, et al. « Geomorphologic evidence for the late Pliocene onset of hyperaridity in the Atacama Desert ». Bulletin of the Geological Society of America, 2012, vol. 124, n 7-8, p. 1048-1070.

Anguera, María, « La observación participante » En: Ángel Aguirre (Editor), Etnografía. Metodología cualitativa en la investigación sociocultural, Ciudad de México, Alfaomega Grupo Editor, 1997, p. 73-85.

Anguera, María, Behar, Julia, Blanco, Ángel, et al. Metodología observacional en la investigación psicológica, Barcelona, Promociones y Publicaciones Universitarias (PPU), 1993.

Barnard, Hans and Dooley, Alek. « An Ancient Irrigation Canal in the Pampa Tamarugal (Chile) », Journal of field Archaeology, 2017, vol. 42, n 4, p. 259-268.

Bauer, Carl, Against de current? Privatization, markets and State in water rigths in Chile: 1979-1993, Tesis para optar al grado de Doctor, California, University of California/Berkeley, 1995.

Berkes, Fikret and Folke, Carl. Linking Social and Ecological Systems Management Practices and Social Mechanisms for Building Resilience. Cambridge, Cambridge University Press, 2000.

Bermúdez, Oscar. Historia del salitre, desde sus orígenes hasta la Guerra del Pacífico, Santiago, Ediciones Universidad de Chile, 1963.

Boelens, Rutgerd, « Cultural politics and the hydrosocial cycle: Water, power and identity in the Andean highlands ». Geoforum, 2014, vol. 57, p. 234-247.

Boelens, Rutgerd, Hoogesteger, Jaime, Swyngedouw, Erik, et al. « Hydrosocial territories: a polítical ecology perspective ». Water International, 2016, vol. 41, issue 1, p. 1-14.

Borrero, Ana, « Paisajes culturales y sus enfoques desde la interdisciplinariedad, una mirada desde la historia y la geografía » En: Flacso (Memorias del I Encuentro de Expertos), Paisajes Culturales: Reflexiones conceptuales y metodológicas, Quito, Flacso, 2012, p. 25-30.

Bouysse-Cassagne, Teresa y Chacama, Juan. « Partición colonial del territorio, cultos funerarios y memoria ancestral en Carangas y precordillera de Arica (siglos XVI-XVII) ", Chungara, Revista de Antropología Chilena, 2012, vol. 44, nº 4, p. 669-689.

Budds, Jessica, « Power, nature and neoliberalism: the political ecology of water in Chile », Singapore Journal of Tropical Geography, 2004, vol. 25, n 3, p. 322-342. 
Budds, Jessica, «Contested $\mathrm{H}_{2} \mathrm{O}$ : Science, policy and politics in water resources management in Chile ", Geoforum, 2009, vol. 40, n³ 3, p. 418-430.

Castro, Luis, Modernización y conflicto social. La expropiación de las aguas de regadío a los campesinos del valle de Quisma (Oasis de Pica) y el abastecimiento fiscal a Iquique, 1880-1937, Valparaíso, Ediciones Universidad de Valparaíso, 2010.

Donoso, Carlos, « Prosperidad y decadencia del mineral de Huantajaya: una aproximación », Revista Diálogo Andino, 2008, n³2, p. 59-70.

Elden, Stuart. « Land, terrain, territory ». Progress in Human Geography, 2010, vol. 34, issue 6, p. 799-817.

Fajardo, Mario. Análisis de tierras utilizables. Pampa Lirima - Salar del Huasco y Quebradas de Tarapacá y Coscaya. Santiago. Centro de Investigación de la Realidad del Norte Grande (CREAR) - Centro de Información de Recursos Naturales (CIREN), 1982.

Garreaud, René, Vuille, Mathias and Clement, Amy, « The climate of the Altiplano: observed current conditions and mechanisms of past changes ». Palaeogeography, Palaeoclimatology, Palaeoecology, 2003, $n^{\circ}$ 194, p. 5-22.

Gayo, Eugenia, Latorre, Claudio, Santoro, Calogero, et al. « Hydroclimate variability in the lowelevation Atacama Desert over the last 2500 yr. » Climate of the past, 2012a, n 8, p. 287-306.

Gayo, Eugenia, Latorre, Claudio, Jordan, Teresa, et al. « Late quaternary hydrological and ecological changes in the hyperarid core of the northern Atacama Desert ", Earth Sciences Review, 2012 b, nº 113 , p. 120-140.

Ghiotti, Stéphane, Les territoires de l'eau : gestion et développement en France. Paris. CNRS, 2007. Giraut, Frédéric, « Territoire multisitué, complexité territoriale et postmodernité territoriale : Des concepts opératoires pour rendre compte des territorialités contemporaines? », L'Espace Géograhique, 2013, Tomo 42, p. 293-305.

Godoy, Milton y Méndez, Manuel, « “Apenas tenemos el agua suficiente para nuestras máquinas”: Estado, minería y tecnologías hídricas en el Desierto de Atacama », Taltal, 1870-1930, Caravelle, $2018, n^{\circ} 111$, p. 25-40.

González, Héctor y Gundermann, Hans, « Acceso a la propiedad de la tierra, comunidad e identidades colectivas entre los aymaras del norte de Chile (1821-1930) », Chungara, Revista de Antropología Chilena, 2009, vol. 41, nº 1, p. 51-70.

González, Sergio, Chilenizando a Tunupa. La escuela pública en el Tarapacá Andino 1880-1990, Santiago, DIBAM, 2002.

Guber, Rosana, La etnografía. Método, campo y reflexividad, Bogotá, Grupo Editorial Norma, 2001. Gundermann, Hans, « La formación del espacio andino en Arica y Tarapacá ». Revista de Historia Indígena, $2003, \mathrm{n}^{\circ}$ 7, p. 87-138.

Gundermann, Hans, «Comunidad Aymara y conflicto interno sobre la tierra en la región de Tarapacá-Chile », Cuadernos Interculturales, 2005, vol. 3, n 5, p. 43-66

Harvey, David, Justice, nature and the geography of difference, New Jersey, Blackwell Publishing, 1996.

Hidalgo, Jorge, « Proyectos coloniales inéditos de riego del desierto: Azapa (Cabildo de Arica, 1619); Pampa Iluga (O’Brien, 1765) y Tarapacá (Mendizabal, 1807) », Chungara, Revista de Antropologia chilena, 1985, $\mathrm{n}^{\circ}$ 14, p. 183-222. 
Houston, John, « Evaporation in the Atacama Desert: An empirical study of spatio-temporal variations and their causes », Journal of Hydrology, 2006, n 330, p. 402-412.

Japan International Cooperation Agency (JICA), The study on the development of water resources in northern Chile, Tokio, Pacific Consultants International, Tokio (Main Report), 1995.

Jordan, Teresa, Kirk-Lawlor, Naomi, Blanco, Nicolás, et al. « Landscape modification in response to repeated onset of hyperaridity paleoclimate states since $14 \mathrm{Ma}$, Atacama Desert, Chile », Bulletin of the Geological Society of America, 2014, vol. 126, $\mathrm{n}^{\circ}$ 7-8, p. 1016-1046.

Lansing, Stephen, Priests and programmers. Technologies of power in the engineered landscape of Bali, Princeton, Princeton University Press, 2007.

Ledru, Marie-Pierre, Jomelli, Vincent, Saramaniego, Patricio, et al. « The Medieval Climate Anomaly and the Little Ice Age in the eastern Ecuadorian Andes ", Climate of the Past, 2013, n 9, p. 307-321.

Lefebvre, Henri, La production de l'espace (Quatrième edition), Paris, Editorial Anthropos, 2000.

Lehmann, Sophie, Climatic and tectonic implications of a mid-miocene landscape: Examination of the Tarapacá pediplan, Atacama Desert, Chile, Tesis para optar al grado de Magíster en Geología. Miami, Miami University, 2013.

Linton, Jamie, What is water. The history of a modern abstraction, Vancouver, The University of British Columbia Press, 2010.

Marquet, Pablo, Santoro, Calogero, Latorre, Claudio, et al. « Emergence of social complexity among coastal hunter-gatherers in the Atacama Desert of northern Chile », Proceedings of the National Academy of Sciences of the United States of America (PNAS), 2012, vol. 109, n 37, p.

14754-14760.

Méndez, Manuel, « Springs, “donkeys” and pumps. Entanglements of discourses and materialities in hegemonic waterscapes of the Atacama Desert, northern Chile ( $19^{\text {th }}$ and early $20^{\text {th }}$ centuries) ", Annual meeting of the American Association of Geographers (AAG), 2019, Washington DC, Poster.

Méndez, Manuel y Romero, Hugo, « Construcción de los territorios altoandinos de Tarapacá, norte de Chile. Reflexión conceptual desde una perspectiva histórica-geográfica », Revista Chilena de Antropología, 2018, n³ 37, p. 183-196.

Méndez, Manuel et Romero, Hugo, « Législation néolibérale et privatisation de la nature. L'irréversible assèchement des zones humides andines (nord du Chili) ». Études Rurales, 2019, $n^{\circ} 203$, p. 126-147.

Mendonça, Magaly, « Monzón sudamericano: la integración de la circulación amazónica y altiplánica y las variabilidades climáticas del altiplano andino chileno ». Revista Diálogo Andino, $2017, \mathrm{n}^{\circ} 54$, p. 21-30

Messerli, Bruno, Grosjean, Martin, Bonani, Georges, et al. « Climate change and resource dynamics of the Atacama altiplano during the last 18.000 years: A preliminary synthesis », Mountain Research and Development, 1997, vol. 13, p. 117-127.

Molina, Francisco, «Competing rationalities in water conflict: Mining and the indigenous community in Chiu Chiu, El Loa Province, northern Chile », Singapore Journal of Tropical Geography, 2004, vol. 33, nº 1, p. 93-107.

Murra, John, « El 'control vertical' de un máximo de pisos ecológicos en la economía de las sociedades andinas » En: Ortíz de Zúñiga, I. Visita de la Provincia de León de Huánuco en 1562 (Volumen 2), Huánuco, Universidad Hermilio Valdizán, 1972, p. 427-476. 
Nester, Peter, Gayo, Eugenia, Latorre, Claudio, et al. « Perennial discharge in the hyperarid Atacama Desert of northern Chile during the late Pleistocene » Proceedings of the National Academy of Sciences of the United States of America (PNAS), 2007, vol. 104, n 50, p. 19724-19729.

Núñez, Lautaro, « Evidencias arcaicas de maíces y cuyes en Tiliviche: hacia el sedentarismo en el litoral fértil y quebradas del norte de Chile », Chungara, Revista de Antropología chilena, 1986, $\mathrm{n}^{\circ} 16-17$, p. $25-49$.

Núñez, Lautaro, Grosjean, Martin, Cartajena, Isabel, « Sequencial analysis of human occupation patterns and resource use in the Atacama Desert ", Chungara, Revista de Antropología chilena, 2010, vol. $42, \mathrm{n}^{\circ} 2$, p. 363-391.

Palacios, Félix, « Marécages artificiels pour alpacas dans le haute puna (l'exemple de Chichillapi) » En : Pierre Morlon (coordinateur), Comprendre l'agriculture paysanne dans les Andes centrales. Pérou-Bolivie, Paris, Institut National de la Recherche Agronomique (INRA), 1992, p. 216-222.

Paz soldán, Mariano, Los verdaderos límites entre el Perú y Bolivia, Lima, Imprenta Liberal, 1878.

Prado, Luis, Los teatros del desierto. Producción del espacio durante el ciclo del salitre. Chile, 1830-1979, Tesis para optar el grado de Doctor en Historia, Barcelona, Universitat Politecnica de Catalunya, 2012.

Prieto, Manuel, « Privatizing water in the Chilean Andes: The case of Las Vegas de Chiu-Chiu », Mountain Research and Development, 2015, vol. 35, n 3, p. 220-229.

Prieto, Manuel, « Bringing water markets down to Chile's Atacama Desert », Water International, 2016, vol. 41, n² 2, p. 191-212.

Romero, Hugo, Méndez, Manuel and Smith, Pamela, (a) « Mining development and environmental injustice in the Atacama Desert of northern Chile », Environmental Justice, 2012, vol. $5, \mathrm{n}^{\circ} 2$, p. 70-76.

Romero, Hugo, Mendonça, Magaly, Méndez, Manuel et al. (b) « Multiescalaridad, relaciones espaciales y desafíos ecológico-sociales de la climatología sudamericana », Revista Brasileira de Climatología, 2012, vol. 8, p. 7-29.

Romero, Hugo, Smith, Pamela, Mendonça, Magaly et al. « Macro y meso climas del altiplano andino y desierto de Atacama: desafío y estrategias de adaptación social ante su variabilidad », Revista de Geografía Norte Grande, 2013, n 55, p. 19-41.

Romero, Hugo, Espinoza, Guillermo, Opazo, Dustyn et al. « Topoclimatología cultural y cambios de clima en la zona andina del Norte de Chile » En: Rafael Sánchez, Rodrigo Hidalgo et al. (compiladores). Re-conociendo las Geografía de América Latina y El Caribe, Santiago, Instituto de Geografía de la Pontificia Universidad Católica de Chile, 2017, p. 93-131.

Ruiz, Jorge, « Análisis sociológico del discurso: métodos y lógicas », Forum: Qualitative Social Research, 2009, vol. 10, n 2, Art.26.

Salinas, Javier, « La comunidad aymara de Cancosa y los acuerdos con la Compañía Minera Cerro Colorado » En: Fernández, Margarita, Salinas, Javier (compiladores). Defensa de los derechos territoriales en Latinoamérica, Santiago, RIL editores, 2012, p. 211-248.

Sanhueza, Cecilia, «Territorios, prácticas rituales y demarcación del espacio en Tarapacá en el siglo XVI », Boletín del Museo Chileno de Arte Precolombino, 2008, vol. 13, n² 2, p. 57-75.

Sarricolea, Pablo y Romero, Hugo, «Variabilidad y cambios climáticos observados y esperados en el Altiplano del Norte de Chile », Revista de Geografía Norte Grande, 2015, nº 62, p. 169-183. 
Sarricolea, Pablo, Meseguer, Oliver y Romero, Hugo, « Tendencias de la precipitación en el norte grande de Chile y su relación con las proyecciones de cambio climático », Revista Diálogo Andino, 2017, $n^{\circ} 54$, p. 41-50.

Santoro, Calogero, Capriles, José, Gayo, et al. « Continuities and discontinuities in the socioenvironmental systems of the Atacama Desert during the last 13,000 years ", Journal of Anthropological Archaeology, 2017, vol. 46, p. 28-39.

Scott, James, Seeing like a State. How certain schemes to improve the human condition have failed, New Haven, Yale University Press, 1998.

Smith, Neil, Uneven development. Nature, capital and the production of space. (Third Edition), Athens, The University of Georgia Press, 2008.

Swyngedouw, Erik, « Modernity and hybridity: nature, regeneracionismo and the production of the Spanish waterscape ", Annals of the American Association of Geographers (AAG), 1999, n 89, p. 443-465.

Swyngedouw, Erik, Liquid power. Contested hydro-modernities in twentieth-century Spain, Cambridge, The Massachusetts Institute of Technology Press, 2015.

Uribe, Mauricio, Sanhueza, Lorena y Bahamondes, Francisco, « La cerámica prehispánica tardía de Tarapacá, sus valles interiores y costa desértica, norte de Chile (CA. 900-1450D.C.): una propuesta tipológica y cronológica ", Chungara, Revista de Antropología chilena, 2007, vol. 39, n², p. 143-170.

Van Kessel, Juan, «La lucha por el agua de Tarapacá: La visión Andina ». Chungara, Revista de Antropología chilena, 1985, n²14, p. 141-155

Van Kessel, Juan, Holocausto al progreso: los Aymaras de Tarapacá, Iquique, IECTA, 2003.

Walker, Brian, Holling, Carl, Carpenter, Stephen et al. « Resilience, adaptability and transformability in social-ecological systems ». Ecology and Society, 2004, Vol.9, $\mathrm{N}^{\circ} 2$

Worster, Donald, Rivers of Empire. Water, aridity, and the growth of the American West, New York, Oxford University Press, 1985.

Yáñez, Nancy y Molina, Raúl, La gran minería y los derechos indígenas en el norte de Chile, Santiago, Editorial LOM, 2008.

Zori, Colleen and Brant, Erika, « Managing the risk of climatic variability in late prehistoric northern Chile », Journal of Anthropological Archaeology, 2012, vol. 31, p. 403-421.

Zori, Colleen, Tropper, Peter and Scott, David, « Copper production in late prehispanic northern Chile », Journal of Archaeology, 2013, vol. 40, p. 1165-1175.

\section{NOTAS}

1. El desarrollo de este artículo se enmarca en el proyecto de investigación "Laboratoire International Associé (LIA) Mines Atacama" del Centro Nacional de la Investigación Científica de Francia (CNRS) y el proyecto FONDECYT N 1150701.

2. De manera general, definiremos como "comunidad" a un grupo social compuesto por dos o más familias, muchas veces emparentadas entre sí, las cuales comparten características culturales y de organización social común, y se encuentran asociadas territorialmente.

3. Una "once comunitaria" es una actividad donde se reúne parte o la totalidad de una comunidad con el fin de compartir bebidas calientes (principalmente té) y comida.

4. Es una ceremonia familiar donde se marcan los animales con llamativos pendientes de lana, para ser reconocidos en los humedales. 
5. Es la segunda fiesta más importante (luego del "año nuevo indígena") de las comunidades quechuas y aymaras. En esta ceremonia se celebra el fin de la temporada húmeda y el comienzo de la temporada seca o de menores recursos. Esta se desarrolla en la cima del cerro sagrado de la comunidad y se agradece a la Pachamama (madre tierra) por los frutos entregados, sacrificando para ellos una llama en su honor.

6. Se entendió como actor clave a los informantes que, por su edad o por los cargos ejercidos anteriormente, contaban con información agregada de cada comunidad y sus segmentos etarios; funcionamiento administrativo y/o social, actividad económica,

7. En nuestra investigación se utiliza la definición del discurso de Ruiz (2009:2), quien propone que discurso es "cualquier práctica por la que los sujetos dotan de sentido a la realidad"

8. Girault (2013:208) propone que los territorios multisituados son "dispositivos espaciales muy coherentes, donde las unidades se encuentran dispersas, pero funcionalmente conectadas, en un espacio producido política e históricamente de manera diferenciada por diferentes segmentos de la sociedad".

9. En términos simples, las Cédulas Reales eran los terrenos que el Estado colonial entregaba a una comunidad (o su representante), sobre la base de su ocupación territorial ancestral (Yáñez N. y R. Molina, 2008)

10. Los humedales altoandinos o bofedales y vegas, son espacios de una alta densidad vegetal, cuyos pastos poseen una gran calidad forrajera, muchos de los cuales se encuentran asociados a vertientes de agua subterránea de origen geotérmica (Ahumada y Faúndez 2009). Aun cuando estas vertientes son de origen natural, los habitantes canalizaban el agua para agrandar y mantener la superficie de estos espacios (Fajardo M., 1982; Palacios F., 1992), lo que transformaba a los humedales en un territorio hidrosocial inserto en la red de territorios multisituados andinos.

11. Pese a la imposición de estas nuevas formas de acceso a la tierra (legislación moderna), al interior de las comunidades altoandinas se mantenía la práctica de construcción territorial sobre la base de sus arreglos culturales particulares. En tal sentido, el acceso al territorio se determinaba a través de su uso, es decir que los territorios de la comunidad eran asignados como espacios de pastoreo de las llamas (Lama glama), las cuales se alimentan de las hierbas de secano, y de las alpacas (Vicugna pacos), que lo hacen de los pastos que se encuentran en bofedales y vegas. En términos de la organización del uso y acceso intracomunitario a estos espacios, los pastos de secano (laderas) son de uso común para todas las familias de la comunidad y los bofedales (bajo riego permanente) tienen un uso familiar exclusivo (la comunidad o Ayllu podía estar compuesta por varias familias) (Méndez M. y H. Romero, 2019).

12. Ya en 1571 Pedro Pizarro señalaba: “en este Tarapacá ay grandes rriquezas de minas encubiertas, que por falta de agua y leña, ni se pueden buscar ni labrar las cubiertas" (citado en Donoso C., 2008; p.62).

13. La intención de ocupar las aguas del valle de Quisma para el abastecimiento de la industria salitrera y la creciente población de la ciudad de Iquique comienza durante la administración peruana (1873). Sin embargo, es el Estado chileno quien materializa esta expropiación en 1924 (Castro L., 2010; Méndez M., 2019)

14. La Guerra del Pacífico (1879-1883) fue un conflicto bélico que involucró a los ejércitos de Bolivia, Chile y Perú. Después de la guerra, que se originó por disputas sobre la propiedad y explotación de nitratos, la Provincia Litoral de Bolivia (actualmente la región de Antofagasta) y las regiones peruanas de Tarapacá y Arica (actualmente las regiones de Tarapacá y Arica-Parinacota, respectivamente) pasaron a ser administradas por Chile.

15. Se denomina "chilenización" al periodo durante el cual el Estado chileno despliega una serie de instrumentos institucionales, legales, culturales, entre otros, destinados a imponer (construir) una nacionalidad y una soberanía chilena entre los habitantes de las recién incorporadas regiones de Antofagasta y Tarapacá. Para un análisis particular de este proceso en la región de Tarapacá ver González (2002).

16. Existe una gran discusión respecto a si las comunidades fueron cooptadas por el contexto sociopolítico y/o ellas incorporan estas características como una "adaptación" a su contexto sociocultural cambiante. En este sentido, se adhiere a la propuesta de Aedo (2008), quien plantea que las poblaciones altoandinas vivieron una intensa reconformación cultural, por lo que no tiene sentido pensar la cultura aymara como un ente puro, aislado de la influencia de la cultura occidental.

17. Principalmente por llevar a sus hijos a desarrollar sus estudios secundarios y la búsqueda de otros estilos de vida "menos duros".

18. Interpretamos este uso comunitario de un humedal como una adaptación a la nueva realidad de la comunidad, donde los habitantes de mayor edad viven en la localidad central.

19. En 1993 la comunidad de Lirima llega a un acuerdo con la comunidad de Cancosa (por el predio de Huantija), quienes con la ayuda económica de CMCC, compran definitivamente estos terrenos (Salinas J., 2012).

20. Aun cuando no poseemos el número exacto comuneros de este rango etario, sobre la base de las entrevistas realizadas se estima que alrededor de un $50 \%$ de este segmento participa activamente en la comunidad. 


\section{RESÚMENES}

Desde la perspectiva de la ecología política se analizan, para distintos periodos históricos, los procesos de producción discursiva y material de los territorios hidrosociales en la zona altiplánica de la región de Tarapacá, situada en el centro del Desierto de Atacama, norte de Chile. Se propone que los procesos conflictuales surgidos durante la producción socionatural de los territorios altoandinos de Tarapacá se encuentran íntimamente ligados a la introducción de las concepciones occidentales del espacio/territorio y del agua, en el marco del proceso de modernización de la región. A través del estudio de caso de los conflictos intra e intercomunitarios de las localidades de Lirima y Cancosa, se pone en contraste la producción ancestral territorial hidrosocial multisituada y la producción moderna del territorio. Sobre la base de los casos de estudio analizados, se propone que la modernización de los territorios en un proceso de larga data, el cual ha simplificado y comodificado las geografías altoandinas de la región.

Depuis la perspective de l'Écologie Politique, les processus de production discursive et production matérielle des territoires hydro-sociaux dans les hauts plateaux andins de la région de Tarapacá, située au centre du désert d'Atacama (nord du Chili), sont analysés pour différentes périodes historiques. Il est proposé que les processus de conflits qui se sont produits pendant la production socio-naturelle des hauts territoires andins de Tarapacá soient étroitement liés à l'introduction des conceptions occidentales de l'espace / territoire et de l'eau, dans le cadre du processus de modernisation de la région. À travers l'étude de cas des conflits intra et intercommunautaires dans les villages de Lirima et Cancosa, la production territoriale ancestrale territoriale multisituée et la production moderne du territoire sont contrastées. Sur la base des études de cas analysées, nous proposons que la modernisation des territoires s'inscrive dans un processus de longue date, lequel a simplifié et marchandise les hauts plateaux andins de la région.

Using the perspective of the Political Ecology this paper analyses, for different historical periods, the processes of discursive and material production of the hydrosocial territories in the High Andean zone of the Tarapacá region, located in the center of the Atacama Desert, northern Chile. It is proposed that the conflict processes that arose during the socionatural production of the high Andean territories of Tarapacá are closely linked to the introduction of the western conceptions of space / territory and water, within the framework of the region's modernization process. Through the study of the inside-community and between communities' conflicts in the villages of Lirima and Cancosa, the multi-situated ancestral way of territorial production and the modern production of the territory are contrasted. Based on these cases analyzed, it is proposed that the modernization of the territories is a long-standing process, which has simplified and commodified the High Andean zone of the region.

\section{ÍNDICE}

Mots-clés: Écologie Politique, Territoires Hydro-Sociaux, Conflits Socio-Environnementaux, Tarapacá, Chili.

Keywords: Political Ecology, Hydro-social territories, socioenvironmental struggles, Tarapacá, Chile

Palabras claves: Ecología Política, Territorios hidrosociales, conflictos socioambientales, Tarapacá, Chile. 


\section{AUTORES}

\section{MANUEL MÉNDEZ}

Doctorando en cotutela: Historia en LAHM-CReAAH, Université de Rennes 2 (Francia) y Antropología en IIAM, Universidad Católica del Norte (Chile).

E-mail: mendez.diaz.manuel@gmail.com

\section{HUGO ROMERO}

Profesor Asociado, Departamento de Geografía Universidad de Chile.

E-mail: hromero@uchilefau.cl 